\title{
Contrast Induced Nephropathy after Radial or Femoral Access for Invasive Management of Acute Coronary Syndrome
}

\author{
Neveen I. Samy1', Walaafareed1, Ahmed Abdelbaky S. Ahmed2, Mohamed Osama² \\ ${ }^{1}$ Cardiovascular Department, Faculty of Medicine, Menoufia University, Al Minufya, Egypt \\ ${ }^{2}$ National Heart Institute (NHI), Giza, Egypt \\ Email: neveinsami@yahoo.com
}

How to cite this paper: Samy, N.I., Walaafareed, Ahmed, A.A.S. and Osama, M. (2019) Contrast Induced Nephropathy after Radial or Femoral Access for Invasive Management of Acute Coronary Syndrome. World Journal of Cardiovascular Diseases, 9, 572-583.

https://doi.org/10.4236/wjcd.2019.98050

Received: May 18, 2019

Accepted: August 18, 2019

Published: August 21, 2019

Copyright $\odot 2019$ by author(s) and Scientific Research Publishing Inc. This work is licensed under the Creative Commons Attribution International License (CC BY 4.0).

http://creativecommons.org/licenses/by/4.0/

\begin{abstract}
Background: Percutaneous coronary intervention is now the best way of management of acute coronary syndrome (ACS). Contrast induced nephropathy is a serious complication and greatly dependent on several factors. It is still unclear whether the vascular access migrates CIN risk. Objective. To study the impact of Radial Access (RA) compared with Femoral Access (FA) on developing contrast-induced nephropathy $(\mathrm{CIN})$ in patients undergoing invasive management of acute coronary syndrome (ACS). Methods. Sixty patients eligible for invasive management of ACS at cardiology department (Menoufia University hospital and National Heart Institute) were randomized into two groups. Group I: included 30 patients with femoral approach and Group II: included 30 patients with radial approach. The occurrence of CIN estimated by KDIGO definition (absolute increase in serum creatinine ( $\mathrm{SCr}$ ) by $\geq 0.5 \mathrm{mg} / \mathrm{dl}$ within 48 hours; or increase in SCr to $\geq 25 \%$ of baseline) was estimated in both groups. Results. Only 9 patients (15\%) developed CIN, 5 patients (55.6\%) of them underwent PCI through FA without statistically significant difference between the two approaches. Conclusion: CIN is considered a potential complication of percutaneous coronary intervention (PCI). Our study did not show the preference of using an approach over the other.
\end{abstract}

\section{Keywords}

Contrast Induced Nephropathy, Serum, Creatinine, Percutaneous Coronary Intervention

\section{Introduction}

Acute coronary syndrome (ACS) refers to a spectrum of clinical presentations 
ranging from those for ST-segment elevation myocardial infarction (STEMI) to presentations found in non-ST-segment elevation myocardial infarction (NSTEMI) or in unstable angina. It is almost always associated with rupture of an atherosclerotic plaque and partial or complete thrombosis of the infarct-related artery (IRA) [1]. ECG and cardiac enzymes are the most important Emergency Department (ED) diagnostic test for ACS then echocardiogram can also help in defining the extent of infarction and in assessing overall ventricular function [2] [3] [4] [5].

Percutaneous coronary intervention (PCI) is the preferred reperfusion strategy in patients with acute ACS and that was done with our STEMI patients while early invasive strategy (within $24 \mathrm{hrs)} \mathrm{with} \mathrm{NSEMI.} \mathrm{PCI} \mathrm{is} \mathrm{superior} \mathrm{to} \mathrm{hospital}$ fibrinolysis with more effective restoration of patency, less re-occlusion, improved residual left ventricular (LV) function and better clinical outcome [6]. There are two accesses for coronary intervention, Trans-femoral approach (TFA) which may be associated with some complications as retroperitoneal hematoma and Trans-radial approach (TRA) which is becoming most preferable to cardiologists due to being less invasive and more comfortable for patients [7] [8].

Contrast induced nephropathy (CIN) is the acute impairment of renal function further to the intravascular administration of contrast media (CM). CIN with subsequent acute kidney injury (AKI) has been associated with the development of acute renal failure, worsening of chronic kidney disease, possible requirement for dialysis, prolonged hospital stay and higher health care cost and mortality rates [9]. The most widely used definition is the increase in serum creatinine $\geq 0.5 \mathrm{mg} / \mathrm{dL}$ or a $25 \%$ increase of SCr from the baseline value $48 \mathrm{hrs}$ after $\mathrm{CM}$ administration [10]. Incidence of CIN is ranging from $2 \%$ to $25 \%$ after $\mathrm{CM}$ injection and explained by renal vasoconstriction resulting in medullary hypoxia, possibly mediated by alterations in nitric oxide, endothelin, or adenosine, and the direct result of the cytotoxic effects of the contrast agents [11].

Many recent studies had discussed the impact of selected approach on incidence of CIN. Lucia Barbeiri et al., is the first large study showing the absence of relationship between the angiographic access and the incidence of CIN, while other studies supported TRA in minimizing incidence of CIN as Matrix-AKI which reported that periprocedural bleeding may be the reason of that significant difference [12] [13].

\section{Patients and Methods}

- This is a prospective study that was carried out from January 2018 till December 2018 and comprised 60 patients who were admitted with ACS and were eligible for invasive management of ACS in Menoufia university hospitals and National Heart Institute. All ACS patients recruited in this study underwent either early invasive management (within $24 \mathrm{hrs)} \mathrm{for} \mathrm{NSTEMI} \mathrm{or}$ primary PCI for STEMI.

Our patients were divided according to interventional access into two groups; 
Group I was (femoral approach group) and group II was (radial approach group).

(The protocol was approved by Menoufia University Ethics Committee and all patients gave written informed consent before participation). Ruling out Patients with missed or unreported baseline SCr, chronic kidney disease (CKD), previous dialysis or any patient with $\mathrm{SCr} \geq 1.5 \mathrm{mg} / \mathrm{dL}$ on reference range $1.5 \mathrm{mg} / \mathrm{dl}$ or patients with any medication (nephrotoxic drugs) that could potentially interfere with SCr level and patients with immunological disease or hematological disorders affecting coagulation profile. Our patients were divided according to interventional access into two groups, the first one was femoral group (30 patients) and the second was radial group (30 patients). All ACS patients recruited in this study underwent either early invasive management (within $24 \mathrm{hrs)}$ ) for NSTEMI or primary PCI for STEMI.

Careful history was taken from all subjects especially risk factors of coronary artery disease (CAD), hypertension, diabetes mellitus (DM), smoking, dyslipidemia, family history of CAD and medical history of any cardiovascular drug or any medication (especially nephrotoxic drugs) as current use of steroid or non-steroid anti-inflammatory drugs and oral anti-diabetic drugs as metformin. Thorough general physical examination and local cardiac examination were done for each patient.

- Resting 12 leads Electrocardiogram (ECG) and Laboratory investigations were done including SCr, blood glucose level and Cardiac enzymes. SCr levels done by taking two separate samples, the first one is (pre-PCI) and the other is (48 hrs, post-PCI). Transthoracic echocardiography was done within 12 hours of admission with assessment of left ventricular ejection fraction (EF\%) and detection of wall motion abnormalities.

- After receiving Aspirin $300 \mathrm{mg}$, clopidogrel $600 \mathrm{mg}$ and intravenous bolus of Heparin 5000 - 10,000 units for all patients, Coronary angiography performed using Judkins technique through femoral artery access or through radial artery access (according to feasibility and cardiologist opinion, the vascular access was established).

Coronary angiograms were analyzed by 2 experienced interventional cardiologists to assess the extent of CAD, Site of the culprit lesion and possible plans of revascularization (culprit versus total).

All STEMI patients were subjected to primary intervention aiming at salvage of the myocardium at the distribution of IRA, while all NSTEMI members early invasive strategy within $24 \mathrm{hrs}$ of chest pain. Variety of guiding catheters and guide wires were used. Balloon and stent size selection was primarily based on visual assessment of vessel size and lesion length. Stent type was determined by the individual operator.

Data was summarized using mean and standard deviation for quantitative variables and frequencies (number of cases) and relative frequencies (percentages) for categorical variables. Comparisons between groups were done using analysis of variance unpaired $t$ test in normally distributed quantitative variables while non-parametric Mann-Whitney test was used for non-normally distributed quan- 
titative variables (Chan, 2003a). For comparing categorical data, Chi square $\left(\chi^{2}\right)$ test was performed. Exact test was used instead when the expected frequency is less than 5 (Chan, 2003b). Logistic regression was done to detect association between redial approach and AKI (Chan, 2004). p-values less than 0.05 were considered as statistically significant.

\section{Results}

Data from 60 patients was recorded ( $75 \%$ males and $25 \%$ females).

STEMI patients representing $63.3 \%$ of the study population had primary PCI and NSTEMI patients representing $36.7 \%$ had early invasive strategy (within $24 \mathrm{hrs}$ ).

Among our study population, only 9 patients representing (15\%) had discovered an absolute $0.5 \mathrm{mg}$ increase or relative elevation of $25 \%$ of base line SCr, in opposition to 51 patients (85\%) did not express that elevation.

Upon dividing patients population into CIN \& Non-CIN groups to estimate the different factors related to appearance of CIN, we found that the percentage of Diabetics was higher in the group of CIN than the group of Non-CIN with significant difference $(\mathrm{p}=0.007)$ (Table 1$)$.

Old age had showed statistically significant difference $(\mathrm{p}=0.008)$ as it was $(61.89 \pm 8.75$ years $)$ in CIN group and $(52.90 \pm 9.13$ years $)$ in Non-CIN patients. It was clearly noted that there is statistically significant difference $(\mathrm{p}<0.001)$ regarding duration of procedure, as it was (65.56 \pm 18.62 minutes) in CIN patients and (47.94 \pm 11.92 minutes) in Non-CIN patients. Also CM amount showed significant difference $(\mathrm{p}<0.001)$ as the amount used in CIN group $(233.33 \pm 36.06$ $\mathrm{ml})$ and $(174.51 \pm 32.33 \mathrm{ml})$ in Non-CIN patients (Table 2).

On comparison between the radial and femoral approaches groups, there was significant difference between the two groups as regard gender $(p=0.037)$, concerning Diabetes, Hypertension and Dyslipidemia did not show significant difference between the two groups ( $\mathrm{p}=0.190, \mathrm{p}=0.243, \mathrm{p}=0.598$ respectively) (Table 3).

Table 1. Risk factors distribution among the CIN \& Non-CIN groups.

\begin{tabular}{|c|c|c|c|c|c|c|}
\hline & & \multicolumn{4}{|c|}{ CIN } & \multirow{3}{*}{$p$ value } \\
\hline & & \multicolumn{2}{|c|}{ Yes } & \multicolumn{2}{|c|}{ No } & \\
\hline & & Count 9 & $\% 15 \%$ & Count 51 & $\% 85 \%$ & \\
\hline \multirow{2}{*}{ Group } & Femoral approach & 5 & $55.6 \%$ & 25 & $49.0 \%$ & \multirow{2}{*}{1} \\
\hline & Radial approach & 4 & $44.4 \%$ & 26 & $51.0 \%$ & \\
\hline \multirow[b]{2}{*}{ Sex } & $\mathbf{M}$ & 8 & $88.9 \%$ & 37 & $72.5 \%$ & \multirow[b]{2}{*}{0.427} \\
\hline & $\mathrm{F}$ & 1 & $11.1 \%$ & 14 & $27.5 \%$ & \\
\hline \multirow{2}{*}{ Diabetes } & Yes & 9 & $100.0 \%$ & 26 & $51.0 \%$ & \multirow{2}{*}{0.007} \\
\hline & No & 0 & $0.0 \%$ & 25 & $49.0 \%$ & \\
\hline \multirow{2}{*}{ Hypertension } & Yes & 8 & $88.9 \%$ & 36 & $70.6 \%$ & \multirow{2}{*}{0.422} \\
\hline & No & 1 & $11.1 \%$ & 15 & $29.4 \%$ & \\
\hline
\end{tabular}


Table 2. Age distribution, duration of PCI \& CM amount among CIN \& Non-CIN groups.

\begin{tabular}{cccccc}
\hline & \multicolumn{5}{c}{ CIN } \\
\cline { 2 - 6 } & \multicolumn{2}{c}{ Yes (9 patients) } & No (51 patients) & p value \\
\cline { 2 - 6 } & Mean & $\begin{array}{c}\text { Standard } \\
\text { deviation }\end{array}$ & Mean & $\begin{array}{c}\text { Standard } \\
\text { deviation }\end{array}$ \\
\hline Age (years) & 61.89 & 8.75 & 52.90 & 9.13 & 0.008 \\
Duration of procedure (min) & 65.56 & 18.62 & 47.94 & 11.92 & $<0.001$ \\
Contrast amount (ml) & 233.33 & 36.06 & 174.51 & 32.33 & $<0.001$ \\
\hline
\end{tabular}

PCI: percutaneous coronary intervention; CM: contrast media; ML: milliliter.

Table 3. Descriptive statistics of risk factors among the studied groups.

\begin{tabular}{|c|c|c|c|c|c|c|}
\hline & & \multicolumn{4}{|c|}{ Group } & \multirow{3}{*}{$\mathrm{p}$ value } \\
\hline & & \multicolumn{2}{|c|}{ Femoral approach } & \multicolumn{2}{|c|}{ Radial approach } & \\
\hline & & Count & $\%$ & Count & $\%$ & \\
\hline \multirow{2}{*}{ Sex } & $\mathbf{M}$ & 19 & $63.3 \%$ & 26 & $86.7 \%$ & \multirow{2}{*}{0.037} \\
\hline & $\mathrm{F}$ & 11 & $36.7 \%$ & 4 & $13.3 \%$ & \\
\hline \multirow{2}{*}{ Diabetes } & Yes & 15 & $50.0 \%$ & 20 & $66.7 \%$ & \multirow{2}{*}{0.190} \\
\hline & No & 15 & $50.0 \%$ & 10 & $33.3 \%$ & \\
\hline \multirow{2}{*}{ Hypertension } & Yes & 24 & $80.0 \%$ & 20 & $66.7 \%$ & \multirow{2}{*}{0.243} \\
\hline & No & 6 & $20.0 \%$ & 10 & $33.3 \%$ & \\
\hline \multirow{2}{*}{ Dyslipidemia } & Yes & 19 & $63.3 \%$ & 17 & $56.7 \%$ & \multirow{2}{*}{0.598} \\
\hline & No & 11 & $36.7 \%$ & 13 & $43.3 \%$ & \\
\hline \multirow{2}{*}{ Smoking } & Yes & 21 & $70.0 \%$ & 25 & $83.3 \%$ & \multirow{2}{*}{0.222} \\
\hline & No & 9 & $30.0 \%$ & 5 & $16.7 \%$ & \\
\hline \multirow{2}{*}{ Family History } & Yes & 19 & $63.3 \%$ & 19 & $63.3 \%$ & \multirow{2}{*}{1} \\
\hline & No & 11 & $36.7 \%$ & 11 & $36.7 \%$ & \\
\hline
\end{tabular}

SCr (pre \& post PCI) level as well EF\% did not show significant difference between the two groups (Table 4).

Within the study, noticed that TIMI flow (pre \& post) and thrombus grade didn't differ between study groups ( $\mathrm{p}=0.423, \mathrm{p}=1.0, \mathrm{p}=0.924$ respectively).

Regarding to pre PCI TIMI flow, 25 subjects were TIMI 0 or 1, representing $41.7 \%$ of the study population. Femoral group included 15 (50\%) patients with TIMI 0 or 1.

Regarding to post PCI TIMI flow, 10 subjects were TIMI 2, representing $(16.7 \%)$ of the study population and $50(83.3 \%)$ subjects were TIMI 3 . Thrombus grade was variable among the study populations, 11 subjects were grade 0 (18.3\%), 17 subjects were grade 3 (28.3\%).

Also the number of stents used in the intervention didn't show significant difference between the two groups ( $\mathrm{p}=0.184), 37$ subjects had only one stent representing $(61.7 \%)$ of the study population and 23 (38.3\%) patients needed two stents. Femoral group included 16(53.3\%) with one stent while in radial group, 21 (70\%) patients had one stent (Table $5 \&$ Table 6). 
Table 4. SCr (pre-PCI) vs (48 hr, post-PCI) \& EF of the studied groups.

\begin{tabular}{cccc}
\hline & $\begin{array}{c}\text { Femoral Group } \\
\text { (Group I) }\end{array}$ & $\begin{array}{c}\text { Radial Group } \\
\text { (Group II) }\end{array}$ & p Value \\
\hline SCr (pre-PCI) & $0.88 \pm 0.15 \mathrm{mg} / \mathrm{dl}$ & $0.93 \pm 0.18 \mathrm{mg} / \mathrm{dl}$ & 0.300 \\
$\mathrm{SCr}$ (48 hr, post-PCI) & $1.13 \pm 0.40 \mathrm{mg} / \mathrm{dl}$ & $1.12 \pm 0.36 \mathrm{mg} / \mathrm{dl}$ & 0.973 \\
EF\% & $57.07 \% \pm 7.81 \%$ & $59.33 \% \pm 3.20 \%$ & 0.150 \\
\hline
\end{tabular}

SCr: serum creatinine; PCI: percutaneous coronary intervention; EF: ejection fraction.

Table 5. Pre \& post PCI-TIMI flow, thrombus grade and number of stents among the studied groups.

\begin{tabular}{|c|c|c|c|c|c|c|}
\hline & \multicolumn{6}{|c|}{ Group } \\
\hline & & \multicolumn{2}{|c|}{ Femoral approach } & \multicolumn{2}{|c|}{ Radial approach } & \multirow[t]{2}{*}{$\mathrm{p}$ value } \\
\hline & & Count & $\%$ & Count & $\%$ & \\
\hline \multirow{3}{*}{ Pre-PCI TIMI } & 0 or 1 & 15 & $50.0 \%$ & 10 & $33.3 \%$ & \multirow{3}{*}{0.423} \\
\hline & II & 12 & $40.0 \%$ & 17 & $56.7 \%$ & \\
\hline & III & 3 & $10.0 \%$ & 3 & $10.0 \%$ & \\
\hline \multirow{3}{*}{ Post-PCI TIMI } & $0-I$ & 0 & $0 \%$ & 0 & $0 \%$ & \multirow{3}{*}{1} \\
\hline & II & 5 & $16.7 \%$ & 5 & $16.7 \%$ & \\
\hline & III & 25 & $83.3 \%$ & 25 & $83.3 \%$ & \\
\hline \multirow{6}{*}{ Thrombus grade } & 0.00 & 5 & $16.7 \%$ & 6 & $20.0 \%$ & \multirow{6}{*}{0.924} \\
\hline & 1.00 & 3 & $10.0 \%$ & 2 & $6.7 \%$ & \\
\hline & 2.00 & 6 & $20.0 \%$ & 8 & $26.7 \%$ & \\
\hline & 3.00 & 8 & $26.7 \%$ & 9 & $30.0 \%$ & \\
\hline & 4.00 & 3 & $10.0 \%$ & 1 & $3.3 \%$ & \\
\hline & 5.00 & 5 & $16.7 \%$ & 4 & $13.3 \%$ & \\
\hline
\end{tabular}

PCI: percutaneous coronary intervention; TIMI: thrombolysis in myocardial infarction.

Table 6. Number of inserted stents among the studied groups.

\begin{tabular}{lcccccc}
\hline & \multicolumn{6}{c}{ Group } \\
\cline { 3 - 7 } & & \multicolumn{6}{c}{ Femoral approach } & Radial approach & p value \\
\cline { 3 - 7 } & & Count & $\%$ & Count & $\%$ & \\
\hline \multirow{2}{*}{ Number of Stents } & 1 stent & 16 & $53.3 \%$ & 21 & $70.0 \%$ & \multirow{2}{*}{0.184} \\
& $>1$ stent & 14 & $46.7 \%$ & 9 & $30.0 \%$ & \\
\hline
\end{tabular}

\section{Discussion}

Cardiovascular disease is nowadays the first worldwide cause of death, accounting for more than 17.3 million deaths per year in 2013 and is commonly associated with myocardial infarction, a number that is expected to grow to more than 23.6 million by 2030 [14]. CIN is the third most common cause of hospital acquired acute renal injury representing about $11 \%$ of the cases [15] [16]. In our study we aimed to compare the impact of selected approach of PCI (femoral vs 
radial) on the development of CIN. Some studies found significant difference in developing CIN between the two approaches due to presence of technical variation which reflected on important parameters like amount of CM and duration of procedure.

We used the CIN definition recommended by the 2012 kidney disease improving global outcomes (KDIGO) workgroup which defined as: Absolute increase in SCr by $\geq 0.5 \mathrm{mg} / \mathrm{dl}$ within 48 hours; or Increase in SCr to $\geq 25 \%$ of baseline (after excluding other factors that may cause nephropathy, such as nephrotoxins, hypotension, urinary obstruction, or atheromatous emboli) [17].

In our study, 9 of 60 patients (16.7\%) experienced CIN that was matched with the incidence across the literature.

In a study by Marenzi et al. on 179 patients undergoing primary angioplasty for acute myocardial infarction, the incidence of contrast induced-AKI was 19\%. A study performed by Rihal et al. showed that acute myocardial infarction (AMI) within $24 \mathrm{~h}$ before administration of the CM is a risk factor for CIN with subsequent AKI ( $p=0.0006)$ [18] [19]. This study demonstrated that CIN is a frequent complication in AMI, even in patients with a normal baseline renal function. The higher incidence of CIN in the setting of STEMI with primary PCI may be explained by LV dysfunction and hemodynamic instability resulting in impaired systemic perfusion and the impossibility to implement renal prophylactic measures before exposure to CM are key contributing factors to CIN development in this setting (Aspelin, P., Aubry, P., Fransson, S.-G., et al.) [20].

We had noticed that there was direct relation between appearance of CIN and some risk factors of CAD as we find that, $\mathrm{DM} \&$ Old age have strong relation with the development of CIN. All 9 CIN subjects are diabetic and 8 of them are hypertensive and smokers also they were older and more frequently men.

Also CIN was strongly related to long duration technique with a big amount of contrast media.

Many recent studies had discussed the impact of selected approach on incidence of CIN.

Our study did not show significant difference of occurrence of CIN between TFA vs TRA. CIN occurs in (16.6\%) of patients with femoral approach in opposition to $(13.3 \%)$ with radial approach. That is possibly explained by the degree of similarity of predictors and comparable parameters between both of the two studies.

Lucia Barbeiri, Monica Verdoi et al. 2019 (Impact of vascular access on the development of CIN in patients undergoing CA and/or PCI). This is the first large study showing the absence of relationship between the angiographic access and the incidence of CIN. Few data have been reported on impact of vascular access on the occurrence of CIN. This study shows that there is no significance in the selected invasive approach. Among 4199 patients (2284 TFA) vs (1915 TRA), occurrence of CIN was not affected by access site, $p$ value $=0.16$ [21].

Also Kolte, D., Spence, N., Puthawala, M. et al. 2016 (Association of radial versus femoral access with CI-AKI in patients undergoing primary PCI for STEMI) 
with data from 1162 patients undergoing primary PCI for STEMI at two tertiary care centers between 2010 and 2014 showed, the difference between TRA and TFA did not reach statistical significance ( $5.9 \%$ vs. $7.0 \%)$, p value $=0.510$. So the conclusion is TRA [22].

On the other hand, some other studies showed hopeful results in using radial approach as their results show significant reduction in CIN occurrence in radial approach in comparison with femoral approach.

Feldkamp T, Spehlmann ME et al. 2017 (Radial access protects from CIN after cardiac catheterization procedures).

This retrospective study included a, 2937 patients that had undergone cardiac catheterization in, (1141 TRA) and (1796 TFA). The study shows that cardiac catheterization using radial access bears significantly lower risk of CIN than cardiac catheterization via femoral access, $\mathrm{p}<0.001$ [23].

A recent report by (Vora et al.) demonstrated that in patients with chronic kidney disease (CKD), the radial access can lead to a reduced rate of progression to dialysis 1 year after the catheter procedure [24].

Also ToufikMahfood Haddad et al. reported a meta-analysis on the incidence of CIN in TRA compared to TFA in patients undergoing coronary angiography or PCI. The RA was associated with a reduced risk of CIN compared with FA. This might be related to reduction of bleeding events associated with RA [25].

Concerning cardiac catheter procedures, a change of clinical practice in favor of the radial access has already occurred.

\section{Matrix-AKI trial 2011-2014}

Among 8404 patients enrolled in the MATRIX-Access trial from 78 centers. AKI occurred in significantly fewer patients with RA compared with FA. AKI occurred in 634 patients (15.4\%) with RA and 712 patients (17.4\%) with FA (p value $=0.0181$.

Peri-procedural bleeding had a higher incidence of AKI, the severity of which, in turn, correlated closely with the severity of bleeding. The mechanism by which the drop in hemoglobin causes AKI is likely the impairment in renal perfusion due to significant blood loss, regardless of changes in systemic blood pressure.

VojkoKanic, GregorKompara, et al. 2011 to 2016 (AKI in patients with myocardial infarction undergoing PCI using radial versus femoral access).

Data from 3842 MI patients undergoing PCI (2011 to 2016), of which 35.8\% were performed radially and retrospectively analyzed. CIN developed in 5.6\% (TRA) vs $10.1 \%$ (TFA), $\mathrm{p}$ value $=0.001$ [26]

But there was no difference between TRA and TFA, after adjustment for potential confounders, according to the study, the access site was not independently associated with a lower incidence of AKI, early nephroprotective strategies to decrease CIN, such as low contrast volume, crystalloid infusions, measures to ensure optimal hemodynamics, and discontinuation of nephrotoxic drugs, might provide a significant long-term benefit. It is important to note that TRA in patients with MI should only be performed by an experienced radial operator. 
Damluji et al. discussed the relationship between the access and amount of $\mathrm{CM}$, the contrast volume in the RA group was also larger [27].

Wojciechsamul et al. reported the increased CM amount in TRA upon a study of 204 patients, there for at sites where the radial approach is not routine, the risk of larger contrast agent volume usage increases. Thus, in patients at risk of CIN or who have renal deficiency or hypersensitivity to the contrast agent in their medical history, the classical femoral approach should be recommended [28].

\section{Conclusions}

CIN is usually an asymptomatic complication, which diagnosis relies on SCr increase following CM exposition. The physiopathology of CIN is multifactorial and still incompletely understood, making it hard to improve diagnostic and therapeutic tools. The comparison of $\mathrm{CIN}$-incidence between trials is a matter of caution, as the prevalence of risk factors is often quite different among the studies.

CIN after PCI is a multi-factorial phenomenon induced by changes in hemodynamics, nephrotoxic effects of iodinated contrast media and cholesterol embolization into the renal vasculature. In clinical practice, it is difficult to make a distinction between these different subjects.

Our study was aiming to emit the difference between the femoral and radial approaches in developing CIN. Some factors may explain why there is a lower risk of renal complications after TRA.

TRA might minimize the risk of cholesterol embolization to the renal arteries, and maybe that there was a reduction in hypotensive episodes because of significant bleeding or vasovagal responses associated with femoral sheath removal with resultant component of ischemic renal injury.

Our study was unable to account for these differences as it did not show significant difference in minimizing the risk of CIN between the two comparable approaches.

\section{Conflicts of Interest}

The authors declare no conflicts of interest regarding the publication of this paper.

\section{References}

[1] Thygesen, K., Alpert, J.S., Jaffe, A.S., et al. (2012) Third Universal Definition of Myocardial Infarction. Circulation, 126, 2020-2035. https://doi.org/10.1161/CIR.0b013e31826e1058

[2] Antman, E.M., Tanasijevic, M.J., Thompson, B., Schactman, M., McCabe, C.H., Cannon, C.P., et al. (1996) Cardiac-Specific Troponin I Levels to Predict the Risk of Mortality in Patients with Acute Coronary Syndromes. The New England Journal of Medicine, 335, 1342-1349. https://doi.org/10.1056/NEJM199610313351802

[3] Heidenreich, P.A., Alloggiamento, T., Melsop, K., McDonald, K.M., Go, A.S. and Hlatky, M.A. (2001) The Prognostic Value of Troponin in Patients with Non-ST 
Elevation Acute Coronary Syndromes: A Meta-Analysis. Journal of the American College of Cardiology, 38, 478-485. https://doi.org/10.1016/S0735-1097(01)01388-2

[4] Keller, T., Zeller, T., Ojeda, F., et al. (2011) Serial Changes in Highly Sensitive Troponin I Assay and Early Diagnosis of Myocardial Infarction. JAMA, 306, 2684-2493. https://doi.org/10.1001/jama.2011.1896

[5] Damman, P., Holmvang, L., Tijssen, J.G., et al. (2012) Usefulness of the Admission Electrocardiogram to Predict Long-Term Outcomes after Non-ST-Elevation Acute Coronary Syndrome (from the FRISC II, ICTUS, and RITA-3 [FIR] Trials). American Journal of Cardiology, 109, 6-12. https://doi.org/10.1016/j.amjcard.2011.08.002

[6] Keeley, E.C., Boura, J.A. and Grines, C.L. (2003) Primary Angioplasty versus Intravenous Thrombolytic Therapy for Acute Myocardial Infarction: A Quantitative Review of 23 Randomised Trials. The Lancet, 361, 13-20.

https://doi.org/10.1016/S0140-6736(03)12113-7

[7] Tavakol, M., Ashraf, S. and Brener, S.J. (2012) Risks and Complications of Coronary Angiography: A Comprehensive Review. Global Journal of Health Science, 4, 65-93. https://doi.org/10.5539/gjhs.v4n1p65

[8] Bhatty, S., Cooke, R., Shetty, R., et al. (2011) Femoral Vascular Access-Site Complications in the Cardiac Catheterization Laboratory: Diagnosis and Management. In terventional Cardiology Journal, 3, 503-514. https://doi.org/10.2217/ica.11.49

[9] Azzalini, L., Candilio, L., McCullough, P.A., et al. (2017) Current Risk of Contrast-Induced Acute Kidney Injury after Coronary Angiography and Intervention: A Reappraisal of the Literature. Canadian Journal of Cardiology, 33, 1225-1228. https://doi.org/10.1016/j.cjca.2017.07.482

[10] Ribichini, F., Graziani, M., Gambaro, G., et al. (2010) Early Creatinine Shifts Predict Contrast-Induced Nephropathy and Persistent Renal Damage after Angiography. The American Journal of Medicine, 123, 755-763. https://doi.org/10.1016/j.amjmed.2010.02.026

[11] Barrett, B.J. and Parfrey, P.S. (2006) Clinical Practice. Preventing Nephropathy Induced by Contrast Medium. The New England Journal of Medicine, 354, 379-386. https://doi.org/10.1056/NEJMcp050801

[12] Samul, W., Turowska, A., Kwasiborski, P.J., Kowalczyk, P. and Cwetsch, A. (2015) Comparison of Safety of Radial and Femoral Approaches for Coronary Catheterization in Interventional Cardiology. Medical Science Monitor, 21, 1464-1468. https://doi.org/10.12659/MSM.893193

[13] Andò, G., Cortese, B., Russo, F., Rothenbühler, M., Frigoli, E., Gargiulo, G., Briguori, C., Vranckx, P., Leonardi, S., Guiducci, V., Belloni, F., Ferrari, F., de la Torre Hernandez, J.M., Curello, S., Liistro, F., Perkan, A., De Servi, S., Casu, G., Dellavalle, A., Fischetti, D., Micari, A., Loi, B., Mangiacapra, F., Russo, N., Tarantino, F., Saia, F., Heg, D., Windecker, S., Jüni, P., Valgimigli, M. and MATRIX Investigators (2017) Acute Kidney Injury after Radial or Femoral Access for Invasive Acute Coronary Syndromes Management: AKI-MATRIX. Journal of the American College of Cardiology, pii: S0735-1097(17)36897-3.

[14] Roth, G.A., Forouzanfar, M.H., Moran, A.E., Barber, R., Nguyen, G., Feigin, V.L., et al. (2015) Demographic and Epidemiologic Drivers of Global Cardiovascular Mortality. The New England Journal of Medicine, 372, 1333-1341. https://doi.org/10.1056/NEJMoa1406656

[15] Bartholomew, B.A., Harjai, K.J., Dukkipati, S., et al. (2004) Impact of Nephropathy after Percutaneous Coronary Intervention and a Method for Risk Stratification. American Journal of Cardiology, 93, 1515-1519. 
https://doi.org/10.1016/j.amjcard.2004.03.008

[16] Nash, K., Hafeez, A. and Hou, S. (2002) Hospital-Acquired Renal Insufficiency. American Journal of Kidney Diseases, 39, 930-936. https://doi.org/10.1053/ajkd.2002.32766

[17] Kellum, J., Lameire, N., Aspelin, P., et al. (2012) KDIGO Clinical Practice Guideline for Acute Kidney Injury. Kidney International, 2, 1-138.

[18] Marenzi, G., Lauri, G., Assanelli, E., Campodonico, J., De Metrio, M., Marana, I., Grazi, M., Veglia, F. and Bartorelli, A.L. (2004) Contrast-Induced Nephropathy in Patients Undergoing Primary Angioplasty for Acute Myocardial Infarction. Journal of the American College of Cardiology, 44, 1780-1785. https://doi.org/10.1016/j.jacc.2004.07.043

[19] Rihal, C.S., Textor, S.C., Grill, D.E., et al. (2002) Incidence and Prognostic Importance of Acute Renal Failure after Percutaneous Coronary Intervention. Circulation, 105, 2259-2264. https://doi.org/10.1161/01.CIR.0000016043.87291.33

[20] Aspelin, P., Aubry, P., Fransson, S.G., Strasser, R., Willenbrock, R., et al. (2003) Nephrotoxic Effects in High-Risk Patients Undergoing Angiography. New England Journal of Medicine, 348, 491-499. https://doi.org/10.1056/NEJMoa021833

[21] Barbieri, L., Verdoia, M., Nardin, M., Marino, P., Suryapranata, H., De Luca, G. and Novara Atherosclerosis Study Group (NAS) (2017) Gender Difference in the Risk of Contrast-Induced Nephropathy in Patients Undergoing Coronary Angiography or Percutaneous Coronary Intervention. Angiology, 68, 542-546.

https://doi.org/10.1177/0003319716669429

[22] Kolte, D., Spence, N., Puthawala, M., Hyder, O., Tuohy, C.P., Davidson, C.B., et al. (2016) Association of Radial versus Femoral Access with Contrast-Induced Acute Kidney Injury in Patients Undergoing Primary Percutaneous Coronary Intervention for ST-Elevation Myocardial Infarction. Cardiovascular Revascularization Medicine, 17, 546-551. https://doi.org/10.1016/j.carrev.2016.07.008

[23] Valgimigli, M., Gagnor, A., Calabro, P., Frigoli, E., Leonardi, S., Zaro, T., Rubartelli, P., Briguori, C., Ando, G., Repetto, A., Limbruno, U., Cortese, B., Sganzerla, P., Lupi, A., Galli, M., Colangelo, S., Ierna, S., Ausiello, A., Presbitero, P., Sardella, G., Varbella, F., Esposito, G., Santarelli, A., Tresoldi, S., Nazzaro, M., Zingarelli, A., de Cesare, N., Rigattieri, S., Tosi, P., Palmieri, C., Brugaletta, S., Rao, S.V., Heg, D., Rothenbuhler, M., Vranckx, P., Juni, P. and Investigators, M. (2015) Radial versus Femoral Access in Patients with Acute Coronary Syndromes Undergoing Invasive Management: A Randomisedmulticentre Trial. The Lancet, 385, 2465-2476. https://doi.org/10.1016/S0140-6736(15)60292-6

[24] Vora, A.N., Stanislawski, M., Grunwald, G.K., Plomondon, M.E., Rumsfeld, J.S., Maddox, T.M., Vidovich, M.I., Woody, W., Nallamothu, B.K., Gurm, H.S. and Rao, S.V. (2017) Association between Chronic Kidney Disease and Rates of Transfusion and Progression to End-Stage Renal Disease in Patients Undergoing Transradial versus Transfemoral Cardiac Catheterization-An Analysis from the Veterans Affairs Clinical Assessment Reporting and Tracking (CART) Program. Journal of the American Heart Association, 6, e004819. https://doi.org/10.1161/JAHA.116.004819

[25] Feldman, D.N., Swaminathan, R.V., Kaltenbach, L.A., Baklanov, D.V., Kim, L.K., Wong, S.C., Minutello, R.M., Messenger, J.C., Moussa, I., Garratt, K.N., et al. (2013) Adoption of Radial Access and Comparison of Outcomes to Femoral Access in Percutaneous Coronary Intervention: An Updated Report from the National Cardiovascular Data Registry (2007-2012). Circulation, 127, 2295-2306.

https://doi.org/10.1161/CIRCULATIONAHA.112.000536 
[26] Cortese, B., Sciahbasi, A., Sebik, R., Rigattieri, S., Alonzo, A., Silva-Orrego, P., et al. (2014) Comparison of Risk of Acute Kidney Injury after Primary Percutaneous Coronary Interventions with the Transradial Approach versus the Transfemoral Approach (from the PRIPITENA Urban Registry). American Journal of Cardiology, 114, 820-825. https://doi.org/10.1016/j.amjcard.2014.06.010

[27] Marenzi, G., Assanelli, E., Campodonico, J., Lauri, G., Marana, I., De Metrio, M., et al. (2009) Contrast Volume during Primary Percutaneous Coronary Intervention and Subsequent Contrast-Induced Nephropathy and Mortality. Annals of Internal Medicine, 150, 170-177. https://doi.org/10.7326/0003-4819-150-3-200902030-00006

[28] Romagnoli, E., Biondi-Zoccai, G., Sciahbasi, A., et al. (2012) Radial versus Femoral Randomized Investigation in ST-Segment Elevation Acute Coronary Syndrome: The RIFLE-STEACS (Radial versus Femoral Randomized Investigation in ST-Elevation Acute Coronary Syndrome) Study. Journal of the American College of Cardiology, 60, 2481-2489. https://doi.org/10.1016/j.jacc.2012.06.017 